\title{
Roux-en-Y hepaticojejunostomy versus hepaticoduodenostomy after excision of choledochal cyst: A randomized clinical trial and experience in a tertiary care hospital
}

\author{
Ray B. K. ${ }^{1}$, Tripathy P. K. ${ }^{2}$, Mohanty P. K. ${ }^{3}$, Jena P.K. ${ }^{4}$, H. K. Mohanty ${ }^{5}$ \\ ${ }^{1}$ Dr. Banoj Kumar Ray, Senior Resident, ${ }^{2}$ Dr. Prasanta Kumar Tripathy, Assistant Professor, ${ }^{3}$ Dr. Pramod Kumar \\ Mohanty, Associate Professor, ${ }^{4}$ Dr. Pradeep Kumar Jena, Professor, ${ }^{5}$ Dr. Hiranya Kishor Mohanty, Professor, all \\ authors are affiliated with Department of Pediatric Surgery, SVP PG Institute of Pediatrics, SCB Medical College, \\ Cuttack, Odisha, India
}

Address for Correspondence: Dr. Prasanta Kumar Tripathy, E mail: drpktripathy555@gmail.com

\begin{abstract}
Introduction: Excision of choledochal cyst is required to relieve biliary obstruction thereby protecting the liver and pancreas as well as to prevent malignancy in long term. But controversy persists in the two existing techniques of biliary reconstruction after cyst excision. Aim: To analyze the clinical presentation, incidence and types of choledochal cyst and our experience in management of these congenital anomalies. To compare the advantages and disadvantages between two modalities of biliary reconstruction. Methods: A prospective, controlled, clinical trial was conducted on patients with choledochal cyst in a tertiary care pediatric surgery hospital. They were divided into two groups; Group-A: Patients in whom biliary reconstruction was done by Roux-en-Y hepaticojejunostomy, Group-B: Biliary reconstruction done by Hepaticoduodenostomy. The two groups were compared in respect to clinical course, types of cyst, surgical difficulties with special emphasis on operating time, postoperative complications. Results: Choledochal cysts accounted for $0.79 \%$ of total admissions at our institute. Out of 31 admitted cases, 22 cases were enrolled in the study. The number of patients in group A were 10 and in group B were 12. Abdominal pain was the commonest presenting feature and Type I choledochal cyst was the most common finding. The average duration of surgery was less in group B (1 hour $25 \mathrm{~min})$ than in group A ( 2 hours and $10 \mathrm{~min}$ ). Conclusion: Biliary reconstruction by Hepaticoduodenostomy takes significantly less operative time than Roux-en-Y hepaticojejunostomy $(\mathrm{P}<0.05)$ and needs single anastomosis. It is more anatomical, physiological, easy to perform and associated with fewer complications.
\end{abstract}

Key words: Anomalous pancreaticobiliary junction, Cholangitis, Choledochal cyst, Hepaticoduodenostomy, Roux-en-Y hepaticojejunostomy

\section{Introduction}

Choledochal cyst (CC) is a rare congenital malformation of biliary tract [1,2]. There occurs pathological dilatation of extrahepatic and/or intrahepatic biliary tree $[1,3]$. About $85 \%$ of cases are reported below 15 years of age [4]. Todani's classification system containing 5 types of CC is widely accepted at present [5]. Type I consists of saccular or fusiform dilatation of common bile duct (CBD) and type II represents a diverticulum of CBD. Type III, also known as choledochocele is

Manuscript received: $06^{\text {th }}$ July 2017

Reviewed: $14^{\text {th }}$ July 2017

Author Corrected: $20^{\text {th }}$ July 2017

Accepted for Publication: $30^{\text {th }}$ July 2017 described as dilatation of the intraduodenal portion of CBD. Type IVA represents multiple extrahepatic and intrahepatic cysts, but type IVB shows only extrahepatic cysts. Type V, termed as Caroli's disease involves intrahepatic bile duct cysts. Lilly et al. described a variant called Forme fruste $\mathrm{CC}$, in which the child presents with symptoms of $\mathrm{CC}$ and there is anomalous pancreaticobiliary junction (APBJ) without dilatation of biliary ducts [6].

Infants with $\mathrm{CC}$ usually present with jaundice and abdominal lump. Abdominal pain is the most common presentation in older children and 
adolescents [4,7]. Ultrasonography as the initial diagnostic method has a sensitivity of 71 to $97 \%$ $[4,8]$. Contrast enhanced computed tomography (CECT) is an useful imaging method, but MRCP (magnetic resonance cholangiopancreatography) is the diagnostic modality of choice. It accurately visualizes the cyst and ductal structures and reasonably detects APBJ. It is non-invasive and not associated with radiation exposure seen in CT scan. The diagnostic accuracy of MRCP for $\mathrm{CC}$ is 90 $100 \%$ and is the gold standard for diagnosis [4,7]. Management of $\mathrm{CC}$ is developed over the years from simple drainage procedure to complete resection of cyst and biliary tract reconstruction. Excision of $\mathrm{CC}$ is essential to protect the liver, pancreas and prevent development of bile duct and gall bladder cancer $[8,9]$. The outcome of $\mathrm{CC}$ is improved and the long term complications are diminished, but the controversy revolves around biliary reconstruction after excision of the cyst. There are two common modes of reconstruction; Roux-en-Y hepaticojejunostomy (RYHJ) and Hepaticoduodenostomy (HD). Both the procedures carry their inherent problem and surgeons publish their individual preferences $[1,10,11]$. Most of the published studies on $\mathrm{CC}$ in children are retrospective and vast majority of articles are from Japan. With this background the present study was carried out in a tertiary pediatric surgical center in eastern part of India as a prospective, controlled, comparative study. The report highlights the experience in the managing pediatric $\mathrm{CCs}$ in our population. The advantages and disadvantages of two modalities of surgery are compared.

\section{Materials and Methods}

This is a prospective study conducted from August 2014 to July 2016 in the department of pediatric surgery. Patients with choledochal cyst admitted for surgery were enrolled for study. All the patients were subjected to detailed history and thorough clinical examination. Routine hematological investigations like hemogram, liver function test (LFT), coagulation profile and renal function test were performed. Abdominal ultrasonograpy was done in all patients to evaluate biliary system; the type of choledochal cyst, size, contour of proximal ducts, vascular anomaly and hepatic echotexture. CECT was performed in five cases. MRCP was done in 15 patients with choledochal cyst to reveal exact nature of biliary system, pancreaticobiliary common channel and pancreatic duct. The exclusion criteria were as follows:

(i) Age: $>14$ years and $<3$ months.

(ii) Types of choledochal cyst: Type-III (choledochocele), Caroli's disease and 'Forme Fruste' choledochal cyst.

(iii) Choledochal cyst with cholangitis features.

(iv) Choledochal cyst with associated anomalies like cardiac and renal.

(v) Patients unfit for surgery and severe malnutrition.

The parents were fully explained about the nature of the disease, operative procedure, possible complications and consent for treatment was obtained. Patients were operated on general anesthesia by right subcostal incision. Excision of $\mathrm{CC}$ and biliary reconstruction was done in all cases. They were assigned into two groups by simple randomization; Group-A: Biliary reconstruction done by Roux-en-Y hepaticojejunostomy, Group-B: Biliary reconstruction done by hepaticoduodenostomy. The two groups were comparable with respect to age at presentation, sex, type of choledochal cyst and clinical features. The parameters used to compare the results in two groups were operative time, surgical difficulties, postoperative leak, pain, cholangitis, gastritis, duration of hospitalization, morbidity and mortality. Regular follow up was done in OPD along with ultrasonography and LFT. Complaints of the patient and complications after surgery were recorded.

\section{Results}

During the above period thirty-one cases of choledochal cysts were admitted to the department of pediatric surgery. CCs accounted for $0.79 \%$ of total admissions (3927) in our department. Twenty-two cases were enrolled in the study after exclusion criteria. There were 11 male children and 11 female children in this study, the sex ratio being 1:1. The median age at presentation was 5 years. Eleven patients were below 5 years of age and 11 were above 5 years. Total number of patients in group A were 10 and in group B were 12. The mean age at presentation in group A was 5.4 years and in group B was 4.8 years. Abdominal pain was the commonest presenting feature followed by jaundice and lump abdomen [Table-1]. The classic triad of pain, lump and jaundice was seen in 
$22.7 \%$ of our cases. Ultrasonography was done in all cases for diagnosis. MRCP was done in $70 \%$ of cases in group A and $85 \%$ of cases in group B [Figure-1].

Table-1: Clinical presentation of study population

\begin{tabular}{|c|c|c|}
\hline & Group A(RYHJ) & Group B (HD) \\
& $(\mathbf{n}=\mathbf{1 2})$ \\
\hline Abdominal pain & 8 & 9 \\
\hline Jaundice & 4 & 5 \\
\hline Lump & 2 & 3 \\
\hline Classical triad & 2 & 3 \\
\hline
\end{tabular}

Figure-1: MRCP picture showing gross saccular choledochal cyst, Type I

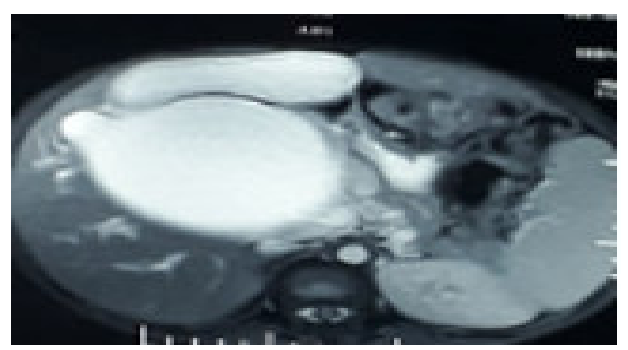

Figure-2(a): Intraoperative photograph showing Type 1 choledochal cyst (b) Hepaticoduodenostomy after cyst excision
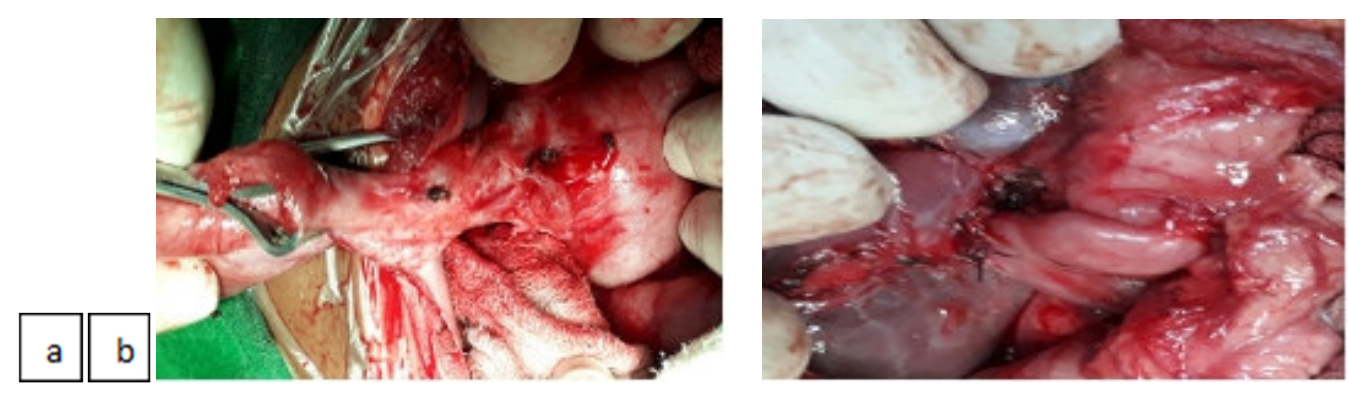

Figure-3: Box plot graph comparing operating time, RYHJ vs HD $(t=3.01, * p=0.006)$

\section{Duration of Surgery in RYHJ vs HD}

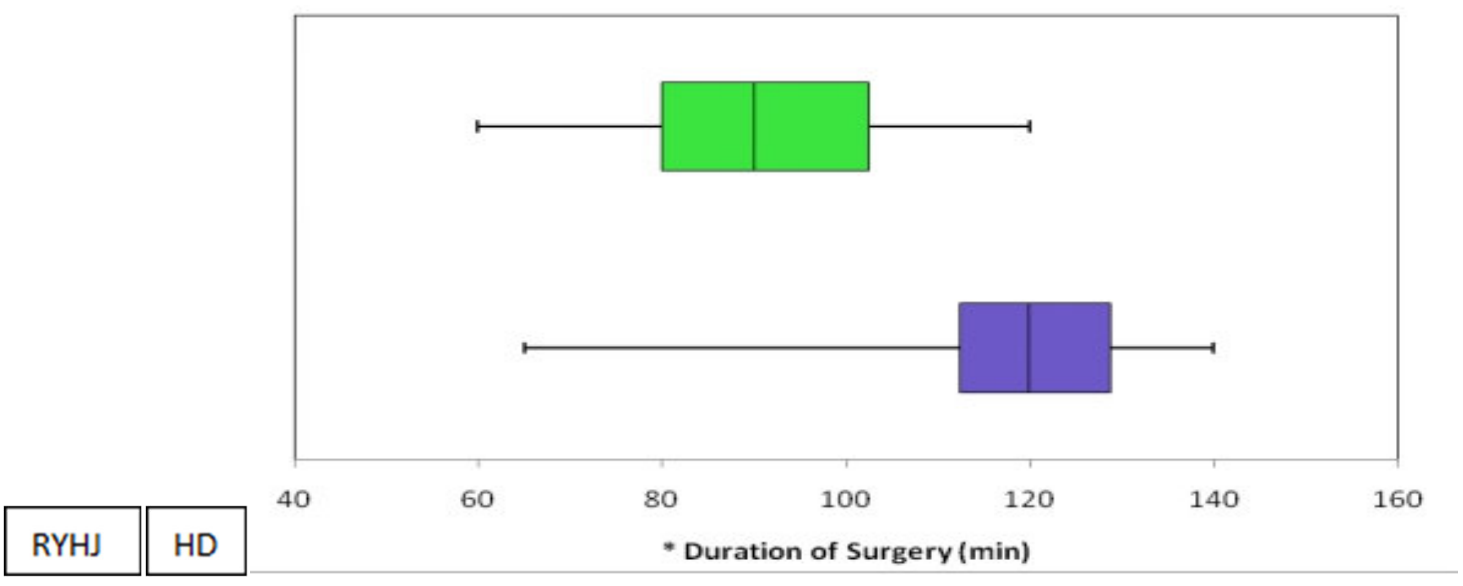


CECT abdomen was done in $20 \%$ of cases in group A and $25 \%$ of cases in group B. Due to poor financial condition both MRCP and CECT could not be done in 2 cases, one from each group. Type I choledochal cyst was the most common finding seen in $77.27 \%$ of cases [Figure-2a,b]. It is followed by Type IVB and Type IVA, but Type II cyst was not detected in this study group. The average operative time was $2 \mathrm{hr} 10 \mathrm{~min}$ in group A and $1 \mathrm{hr}$ $25 \mathrm{~min}$ in group B. The operative time was shorter by $55 \mathrm{~min}(64.7 \%$ less time) in HD group as compared to RYHJ group [Figure-3].

Table-2: Early Postoperative Complications (during hospital stay)

\begin{tabular}{|c|c|c|c|}
\hline Complications & Group A [n=10] & Group B [n=12] & p value \\
\hline Postoperative pain & 4 & 2 & 0.34 \\
\hline Anastomotic leak & 1 & 1 & 1.0 \\
\hline Early cholangitis & 2 & 2 & 1.0 \\
\hline Total & 7 & 5 & 0.23 \\
\hline
\end{tabular}

Table-3: Postoperative Complications (during 1 year follow up)

\begin{tabular}{|c|c|c|c|}
\hline Complications & Group A [n=10] & Group B [n=12] & p value \\
\hline Gastritis & 2 & 3 & 1.0 \\
\hline Cholangitis & 2 & 2 & 1.0 \\
\hline Pancreatitis & 1 & 1 & 1.0 \\
\hline Intestinal Obstruction due to Adhesion & 1 & 0 & 0.45 \\
\hline Intrahepatic Stone Formation & 2 & 1 & 0.57 \\
\hline Total & $\mathbf{8}$ & $\mathbf{7}$ & $\mathbf{0 . 3 8}$ \\
\hline
\end{tabular}

In early postoperative period pain, anastomotic leak and features of cholangitis were seen more commonly in group A patients [Table-2]. Bilious RT aspirate was seen up to 4 days postoperatively in group A and the average time to start oral feeds was 6 days. RT aspirate was bilious upto 3 days on an average in group B patients and the feeding was started on 4 days after surgery. Mean duration of hospitalization was 9 days in both the groups and there was no mortality in any group. During 1 year follow up period reflux gastritis was seen in $20 \%$ of cases of group A and $25 \%$ of cases in group B [Table-3]. Cholangitis was seen in $20 \%$ of cases in group A and $16.6 \%$ of cases in group B. Postoperative adhesive intestinal obstruction was seen in one case in group A. It was managed conservatively in our hospital. Intrahepatic stone formation was seen in two cases in group A and one case in group B. None of our patients had anastomotic stricture or malignancy on follow up.

\section{Discussion}

The incidence of $\mathrm{CC}$ estimated in western population is 1 in 100/150 000 live births $[8,12,13]$ and it is more common in Asian countries especially in Japan $[14,15,16]$. Several theories are proposed for etiology of CC. Babbitt's common channel theory is widely accepted [17]. A long common channel is produced by the union of pancreatic duct and common bile duct outside the ampullla of Vater. The resultant mixture of biliary and pancreatic juice activates pancreatic enzymes, which further causes inflammation and dilatation of biliary duct wall. Here the long common channel is arbitrarily defined and authors describe it as $10 \mathrm{~mm}$ to $45 \mathrm{~mm}[18,19]$. Forme Fruste CC supports this APBJ theory in pathogenesis and complications of CC. But APBJ is present in $50-80 \%$ of patients with CC [18]. Singham et al. described the dilation in $\mathrm{CC}$ to be due to overproduction of epithelial cells during cannulation phase of embryogenesis [19]. Davenport and Basu described a pathological paucity of neurons and ganglions in CC [20]. They proposed that round cysts are congenital and aganglionosis causing distal obstruction is similar to Hirschsprungs disease. Authors also suggest that fusiform dilations are due to acquired APBJ. Pathophysiologically, 3 types of ABPJ have been described by Komi et al; (i) Right angled unionassociated with cystic dilatation of CBD, (ii) Acute angled union- associated with fusiform dilatation of CBD and (iii) Right/ acute angled union with accessory pancreatic duct [21].

The female predominance of this disease is widely reported with female to male ratio of $3-4: 1[1,4,8]$. 
But in the present study sex ratio is $1: 1$. The probable cause of fewer female enrolments could be attributed to less importance being given to female child. The present study shows that, abdominal pain is most common presentation $(77.2 \%)$ followed by jaundice (40.9\%) and abdominal lump (18.2\%). Abdominal pain was also the major presenting feature $(86 \%$ cases $)$ in series reported by Mukhopadhyay et al [22]. Jaundice and abdominal pain were also prominent features in the study by Silva-Baez et al accounting for $78.5 \%$ and $85.7 \%$ of cases respectively [1].

The classic triad of abdominal pain, mass and jaundice is recorded in about 17 to $21.5 \%$ of cases $[22,23]$. However, the triad was present in $22.7 \%$ of our cases. Type I variety is most common type accounting for about $90 \%$ of cysts and it is followed by type IV cysts in frequency $[4,8]$. In the present series Type I accounted for $77.27 \%$ of cases and the remaining were type IV out of which type IVA was $4.45 \%$ and type IVB was $18.18 \%$ of cases. Mukhopadhyay et al. noticed type I cyst accounting for $79.7 \%$ and type IV cysts as $15 \%$ of their series [22]. The types of cyst and age at presentation between the two groups in our series were statistically non-significant.

Historically, internal drainage procedure (Cholecystoenterostomy) was the surgical approach for $\mathrm{CC}$ for decades. Currently this procedure is abandoned due to high risk of complications like cholangitis, pancreatitis and malignancy in upto $50 \%$ of cases $[18,24]$. Reoperation was needed in $70 \%$ of patients due to development of complications [25]. Therefore complete excision of $\mathrm{CC}$ became essential for surgical management. The complications were reduced dramatically along with a decreased incidence of malignancy $(0.7 \%)$ [26]. Lilly's method of cyst excision is needed whenever intense pericystic fibrosis precludes complete resection. The less adherent portion of cyst is removed and densely adherent part of cyst wall retained; the mucosal lining are stripped or ablated by diathermy [27]. Two techniques of hepaticoenterostomy gained popularity; RYHJ and HD. Although appendix interpositioned hepaticoenterostomy was tried in some centers, it failed to be popular. The appendix underwent stenosis and there was biliary obstruction and development of hepatic fibrosis [24]. RYHD is reported to be the preferred method in many centers, but HD is still a simple and easy technique. We compared the advantages and disadvantages of both the procedures so as to opt for an ideal method of biliary reconstruction after excision of $\mathrm{CC}$.

The operative time and duration of anesthesia counts a lot for postoperative morbidity and mortality especially in infants and young children. The average operating time was less in HD group (1 hour \& $25 \mathrm{~min}$ ) as compared to RYHJ group (2 hours \& $10 \mathrm{~min})$. This difference is statistically significant $(\mathrm{p}=0.006)$ and is the major advantage in HD group. The postoperative complications differ from institutions, age of the patient and in different surgical procedures. Anastomotic stricture is reported in $4.1 \%$ of cases following bilioenteric anastomosis for CC [28], but none of our patients have anastomotic stricture. It was due to the fact that, a wide anastomosis was performed between intestine and hilum of liver.

In the present study biliary reflux gastritis was seen to be more marked in HD group (25\%) than RYHJ group $(20 \%)$, but it was not statistically significant. Shimotakahara et al. had also reported high incidence of duodenogastric bile reflux $(33.3 \%)$ in HD patients and they preferred RYHJ for bilioenteric anastomosis [10]. Postoperative cholangitis and adhesive intestinal obstruction were observed more frequently in RYHJ group than HD group in our study. Adhesive bowel obstruction was found on follow up of one of our patients in RYHJ group (10\%) and none in HD group.

Shimotakahara et al. also found this complication in $7.1 \%$ of their series in RYHJ group and none in HD group [10]. Intrahepatic stone formation was seen 10 to $16.7 \%$ of children after cyst excision $[25,29]$ and it was observed in $20 \%$ of our cases in group A and $8.3 \%$ of cases in group B. On comparison between two groups these postoperative complications were not statistically significant. In a recent metaanalysis, Narayanan et al. also found no significant difference in postoperative anastomotic leak, stenosis, cholangitis and adhesive bowel obstruction between HD and RYHJ biliary reconstruction after $\mathrm{CC}$ excision [30].

Although the average duration of hospital stay was equal in both of our groups, authors noted a shorter hospital stay in HD patients [1,30]. The excision of CC significantly reduces the development of 
malignancy, but intrahepatic cholangiocarcinoma is observed on long term follow up [4]. None of our patients developed malignancy on follow up. Mortality after surgery for CC is reported in $1.27 \%$ and $5.7 \% \mathrm{CC}$ patients in series reported by Mukhopadhya et al. and Sharma et al. respectively $[11,22]$. The mortality in the series reported by Mukhopadhya et al. was noted only in RYHJ group. Mortality was not observed in our series, but we observed morbidity of $25 \%$ of patients. Shimotakahara et al. and Todani et al. reported morbidity of $17.5 \%$ and $23.3 \%$ in their respective series [10,31] without any mortality. This prospective study is a reflection of presentation of $\mathrm{CCs}$ in eastern part of India along with the management approach and short term follow up.

The disease is known for typical female preponderance, but the sex ratio is equal in our study population. The classical triad of presentation was recorded more frequently than other series. Surgeons still debate for decades regarding ideal surgical management of $\mathrm{CC}$ and the most common reconstructive technique following excision of Cyst is RYHJ [24]. Mukopadhya et al. described HD as a simple procedure preserving normal anatomy and physiology [22]. But Shimotakahara et al. did not recommend $\mathrm{HD}$ because of high incidence of duodenogastric biliary reflux and other complications [10]. They described RYHJ as their exclusive technique of choice. In this background, we have clearly defined the advantages of HD over RYHJ especially the duration of surgery, which is significantly less in HD group. Presently, HD is our technique of choice for biliary reconstruction after excision of $\mathrm{CC}$.

\section{Conclusion}

Choledochal cyst is an uncommon disease for which resection of the cyst along with a wide bilioenteric anastomosis is essential for better outcome. Biliary reconstruction by $\mathrm{HD}$ takes significantly less operative time than RYHJ $(\mathrm{P}<0.05)$ and needs single anastomosis. It is more anatomical, physiological, easy to perform and associated with fewer complications as compared to RYHJ. A longer study is required to identify further complications in the current surgical practice and to detect development of malignancy.

Contribution by Authors: BKR-Data collection and processing, PKT - Data management and reporting, literature review, logical interpretation and presentation of the results construction of the whole of the manuscript, PKM - Supervising the course of the project, PKJ - Reviewing the article before submission, HKM - Hypothesis for research, planning methodology.

Funding: Nil, Conflict of interest: None initiated, Perission from IRB: Yes

\section{References}

1. Silva-Baez H, Coello-Ramirez P, IxtabalanEscalante M, Sotelo-Anaya E, Gallo-Morales M, Cordero-Estrada E, et al. Treatment of Choledochal cyst in a pediatric population. A single institution experience of 15-years. Case series. Annals of Medicine and Surgery 2016; 5: 81-85. Doi: 10.1016/j.amsu.2015.12.054

2. Thatipamula AB, Moka J. Surgical management of Choledochal cysts in children- Our experience in a district level teaching hospital. International Journal of Anatomy, Radiology and Surgery 2016; 5(4): SO05-08.

3. She WH, Chung HY, Lan LC, Wong KK, Saing H, Tam PK. Management of choledochal cyst: 30 years of experience and results in a single center. J Pediatr Surg. 2009 Dec;44(12):2307-11. doi: 10.1016/j.jpedsurg.2009.07.071.

4. Tadokoro H, Takase M. Recent advances in choledochal cysts. Open Journal of Gastroenterology 2012; 2: 145-154. http://dx.doi.org/10.4236/ojgas.2012.24029

5. Todani T, Watanabe Y, Narusue $M$, et al. Congenital bile duct cyst: Classification, operative procedure, and review of thirty-seven cases including cancer arising from choledochal cyst. Am J Surg 1977; 134(2): 263-9.

6. Lilly JR, Stellin GP, Karrer FM. Forme fruste choledochal cyst. J Pediatr Surg 1985;20(4): 449-51.

7. Liem NT, Holcomb III GW. Choledochal cyst and Gallbladder disease. In: Holcomb III GW, Murphy JP, Ostie DJ. Editors. Ashcraft's Pediatric surgery. $6^{\text {th }}$ ed. Elsevier Saunders 2014. Pp. 593606.

8. Gonzales KD, Lee H. Choledochal Cyst. In: Coran AG, Adzick NS, Krummel TM, Laberge J, 
Shamberger RC, Caldmone AA. Editors. Pediatric Surgery. $7^{\text {th }}$ ed. Elsevier Saunders 2012.pp. 1331-9.

9. Ono S, Fumino S, Shimadera S, Iwai N. Longterm outcomes after hepaticojejunostomy for choledochal cyst: a 10- to 27-year follow-up. J Pediatr Surg. 2010 Feb;45(2):376-8. doi: 10.1016/j.jpedsurg.2009.10.078.

10. Shimotakahara A, Yamataka A, Yanai T, Kobayashi H, Okazaki T, Lane GJ, Miyano T. Roux-en-Y hepaticojejunostomy or hepaticoduodenostomy for biliary reconstruction during the surgical treatment of choledochal cyst: which is better? Pediatr Surg Int. 2005 Jan;21(1):57.

11. Sharma A, Pandey A, Rawat J, Ahmed I, Wakhlu A. Conventional and unconventional surgical modalities for choledochal cyst: Long-term follow-up. Annals of Pediatric Surgery 2011; 7(1): 17-9.

12. Bhavsar MS, Vora HB, Giriyappa VH. Choledochal cysts : a review of literature. Saudi J Gastroenterol. 2012 Jul-Aug;18(4):230-6. doi: $10.4103 / 1319-3767.98425$

13. Howard ER, Choledochal cysts. In: Howard ER. Editor. Surgery of liver disease in children. Butterworth-Heineman, Oxford 1991. Pp. 78-90.

14. Lipsett PA, Pitt HA. Surgical treatment of choledochal cysts. J Hepatobiliary Pancreat Surg. 2003;10(5):352-9.

15. Liu BS, Shu YP, Xing KM, Cheng HP, Ying $\mathrm{BL}$, Xiao PC. Diagnosis and treatment of congenital choledochal cyst: 20 years' experience in China. World J Gastroenterol 2001; 7: 733-4.

16. Miyano T, Yamataka A, Li L. Congenital biliary dilatation. Semin Pediatr Surg. 2000 Nov;9(4):18795.

17. Babbitt DP. [Congenital choledochal cysts: new etiological concept based on anomalous relationships of the common bile duct and pancreatic bulb]. Ann Radiol (Paris). 1969;12(3):231-40.

18. Jabłońska B. Biliary cysts: etiology, diagnosis and management. World J Gastroenterol. 2012 Sep 21;18(35):4801-10.
19. Singham J, Yoshida EM, Scudamore CH. Choledochal cysts: part 1 of 3: classification and pathogenesis. Can J Surg. 2009 Oct;52(5):434-40.

20. Davenport M, Basu R. Under pressure: choledochal malformation manometry. J Pediatr Surg. 2005 Feb;40(2):331-5.

21. Komi N, Takehara H, Kunitomo K, Miyoshi Y, Yagi T. Does the type of anomalous arrangement of pancreaticobiliary ducts influence the surgery and prognosis of choledochal cyst? J Pediatr Surg. 1992;27:728-31. DOI: http://dx.doi.org/10.1016/S0022-3468(05)80102-2

22. Mukhopadhyay B, Shukla RM, Mukhopadhyay M, Mandal KC, Mukherjee PP, Roy D, Biswas SK, Basu KS. Choledochal cyst: A review of 79 cases and the role of hepaticodochoduodenostomy. J Indian Assoc Pediatr Surg. 2011 Apr;16(2):54-7. doi: 10.4103/0971-9261.78131.

23. Lipsett PA, Pitt HA, Colombani PM, Boitnott JK, Cameron JL. Choledochal cyst disease. A changing pattern of presentation. Ann Surg. 1994 Nov;220(5):644-52.

24. Metcalfe MS, Wemyss-Holden SA, Maddern GJ. Management dilemmas with choledochal cysts. Arch Surg. 2003 Mar;138(3):333-9.

25. Chijiiwa K, Koga A. Surgical management and long-term follow-up of patients with choledochal cysts. Am J Surg. 1993 Feb;165(2):238-42.

26. Watanabe Y, Toki A, Todani T. Bile duct cancer developed after cyst excision for choledochal cyst. J Hepatobiliary Pancreat Surg. 1999;6(3):207-12.

27. Lilly JR. The surgical treatment of choledochal cyst. Surg Gynecol Obstet. 1979 Jul;149(1):36-42.

28. Hata Y, Sasaki F, Takahashi H, Tamura M, Ohkawa Y, Saji Y, Kurauchi N, Manabe K, Uchino J. Surgical treatment of congenital biliary dilatation associated with pancreaticobiliary maljunction. Surg Gynecol Obstet. 1993 Jun;176(6):581-7.

29. Yamataka A, Ohshiro K, Okada Y, et al Complications after cyst excision with hepaticoenterostomy for choledochal cysts and their surgical management in children versus adults. J Pediatr Surg 1997; 32: 10971102.Doi:10.1016/S0022-3468(97)90407-3. 
30. Narayanan SK, Chen Y, Narasimhan KL, Cohen RC. Hepaticoduodenostomy versus hepaticojejunostomy after resection of choledochal cyst: a systematic review and meta-analysis. J Pediatr Surg. 2013 Nov;48(11):2336-42. doi: 10.1016/j.jpedsurg.2013.07.020.
31. Todani T, Watanabe Y, Mizuguchi T, Fujii T, Toki A. Hepaticoduodenostomy at the hepatic hilum after excision of choledochal cyst. Am J Surg. 1981 Nov;142(5):584-7.

\section{How to cite this article?}

Ray B. K., Tripathy P. K., Mohanty P. K., Jena P.K., H. K. Mohanty. Roux-en-Y hepaticojejunostomy versus hepaticoduodenostomy after excision of choledochal cyst: A randomized clinical trial and experience in a tertiary care hospital. J PediatrRes.2017;4(07):438-445.doi:10.17511/ijpr.2017.i07.02. 